\title{
Fetomaternal outcome in caesarean section at full dilatation
}

\author{
Kavita Gupta, Apurva Garg*
}

Department of Obstetrics and Gynecology, RNT Medical College, Udaipur, Rajasthan, India

Received: 16 May 2019

Accepted: 01 July 2019

\section{*Correspondence:}

Dr. Apurva Garg,

E-mail: swtgupta583@gmail.com

Copyright: (C) the author(s), publisher and licensee Medip Academy. This is an open-access article distributed under the terms of the Creative Commons Attribution Non-Commercial License, which permits unrestricted non-commercial use, distribution, and reproduction in any medium, provided the original work is properly cited.

\section{ABSTRACT}

Background: To study indications, intraoperative and postoperative complications and fetomaternal outcome in cesarean sections done at full dilatation.

Methods: This is a prospective cross-sectional study which was conducted in the department of obstetrics and gynecology, RNT medical college, Udaipur from November 2018 to April 2019. 100 cases of caesarean sections at full dilatation which were performed during this period were analyzed for indications and maternal and fetal morbidity.

Results: Among these 100 cesarean sections, majority of cases were in the age group of 21-30 years (46\%), booked and Primigravida(81\%).Most common indications were cephalo-pelvic disproportion (27\%) and fetal distress (21\%). Most commonly baby was delivered either by vertex (44\%) or by Patwardhan (31\%). Intraoperative complications were higher in terms of hematuria in $41 \%$, Atonic PPH in $35 \%$, uterine incision extension in $28 \%$ of cases. In one case bladder injury was noticed. Increased incidence of post-operative febrile illness and wound infection were noted. $44 \%$ baby's required nursery admission, most commonly due to birth asphyxia (16\%) and RDS (11\%).

Conclusions: Cesarean section in the $2^{\text {nd }}$ stage of labor is associated with significantly increased maternal morbidity, Neonatal morbidity and mortality. So proper monitoring during labor and involvement of skilled obstetrician in decision making and delivery is crucial to minimize fetomaternal complications.

Keywords: Caesarean section, Maternal morbidity, Neonatal morbidity, Patwardhan method, Second stage of labor

\section{INTRODUCTION}

Cesarean delivery is defined as the birth of the fetus through incisions in the abdominal wall and then uterine wall. It is the most commonly performed operative procedure in obstetrics and the incidence is increasing tremendously which is a cause for concern because cesarean section is associated with higher likelihood of adverse outcome for both mother and fetus as compared to vaginal delivery. ${ }^{1}$

Second stage of labor begins when there is complete cervical dilatation and ends with fetal delivery. ${ }^{2}$ A cesarean section at second stage occurs when mother requires delivery at full dilatation of cervix, which poses a risk to herself and the fetus and cannot be dealt with by

Assisted vaginal delivery. There has been an increase in the incidence of cesarean performed at full dilatation. 3 Multiple etiological factors have been identified for this increasing trend of second stage caesareans like decline in the use of instrumental delivery, lack of training and supervision in second stage decision-making, a loss of technique associated with difficult-assisted delivery and concerns relating to maternal and neonatal morbidity with associated litigious issues. This increasing trend of cesarean at second stage is of major concern in current obstetrics. 
Cesarean section at full dilatation is a technically more challenging procedure than cesarean in early labour.4 It is because the fetal head can be deeply impacted into the pelvis and the lower segment is thinned out and edematous which makes the procedure technically difficult. Caesarean section at full dilatation is associated with high maternal and fetal morbidity. 5,6 The maternal morbidity includes post partum hemorrhage, uterine incision extension, prolonged operating time, injury to bladder, postpartum pyrexia. ${ }^{7,8}$ Neonatal mortality and morbidity is because of hypoxia and fetal trauma causing prolong NICU stay.

The objectives of the present study were to study the indications for second stage caesarean section, methods of delivery of the deeply engaged head, the intra operative and post-operative complications, and perinatal outcome.

\section{METHODS}

This is a prospective cross-sectional study which was conducted in the department of OBG, RNT medical college Udaipur from November 2018 to April 2019. Sample size was 100. Data were collected after taking patient's consent. The results were statistically analyzed by percentage.

\section{Inclusion criteria}

- $\quad$ Primi or multi-gravida with singleton pregnancy

- Period of gestation of $>37$ weeks

- Cephalic presentation

- With/without previous LSCS.

\section{Exclusion criteria}

- Presence -multiple pregnancies

- Preterm deliveries

- Malpresentations

- Maternal co-morbid condition.

Partograph was used to monitor the progress of labor and uterine actions, rate of dilatation of cervix, descent of the presenting part were observed except for those patients who were already referred in the late second stage of labor. Patients who underwent second stage caesarean section were analyzed in terms of indications of $2^{\text {nd }}$ stage caesarean section, intra operative and postoperative complications and neonatal outcome.

\section{RESULTS}

In this study which is based on sample of 100 patients who underwent second stage cesarean, the following were the study results which were analyzed by percentage and reported:

Table 1 shows demographic characteristic of the cases. Among the 100 patient's majority of them were in the age group of 21-30 years (46\%). Majority of the patients were booked and $36 \%$ were un-booked who were from remote areas near the district. $81 \%$ of the patients were primigravida and only $19 \%$ were multigravida.

Table 1: Demographic characters of cases in the study.

\begin{tabular}{|c|c|c|}
\hline Demographic char & $\mathrm{Nu}$ & Percentage \\
\hline \multicolumn{3}{|c|}{ Age wise distribution of cases in study } \\
\hline $18-20$ years & 32 & $33 \%$ \\
\hline 21-30 years & 46 & $46 \%$ \\
\hline $31-34$ years & 21 & $21 \%$ \\
\hline \multicolumn{3}{|l|}{ Antenatal care } \\
\hline Booked & 64 & $64 \%$ \\
\hline Unbooked /referred & 36 & $36 \%$ \\
\hline \multicolumn{3}{|l|}{ Gravida } \\
\hline Primi & 81 & $81 \%$ \\
\hline Multi & 19 & $19 \%$ \\
\hline
\end{tabular}

Table 2: Indications for caesarean sections.

\begin{tabular}{|lll|}
\hline Indication & Number & Percentage \\
\hline Cephalopelvic disproportion & 27 & $27 \%$ \\
\hline Deep transverse arrest & 11 & $11 \%$ \\
\hline Non descent of head & 14 & $14 \%$ \\
\hline Fetal distress & 21 & $21 \%$ \\
\hline Persistent occipito-posterior & 7 & $7 \%$ \\
\hline Deflexed head & 11 & $11 \%$ \\
\hline Obstructed labor & 9 & $9 \%$ \\
\hline
\end{tabular}

Table 2 shows the indications of cesarean section. Most common indications were cephalo-pelvic disproportion (27\%) and fetal distress (21\%).Other were deep transverse arrest, Non descent of head, Persistent occipito-posterior, deflexed head and obstructed labor. Most of the cases of obstructed labor were delayed referral from primary health centers, and district hospitals nearby.

Table 3: Technique of delivery of deeply engaged head.

\begin{tabular}{|lll|}
\hline Technique & Number & Percentage \\
\hline Baby delivered by vertex & 44 & $44 \%$ \\
\hline Patwardhan & 31 & $31 \%$ \\
\hline Push method & 17 & $17 \%$ \\
\hline $\begin{array}{l}\text { Reverse breech extraction } \\
\text { (pull method ) }\end{array}$ & 8 & $8 \%$ \\
\hline
\end{tabular}

Table 3 shows the different techniques of delivery of baby during cesarean section. In our study most commonly, baby was delivered either by vertex (44\%) or by Patwardhan $(31 \%)$. Rest adopted push method or reverse breech extraction.

Table 4 shows intra operative complications. Atonic PPH was observed in $35 \%$ of patients which may be due to 
prolonged second stage of labor and use of inducing agents. Uterine incision extension was observed in $28 \%$ of cases due to operative difficulty in delivery of deeply engaged head and thinned out and edematous lower segment. Angle hematoma was found in $9 \%$ patients and uterine artery was ligated in $13 \%$. Blood was transfused to $8 \%$ of patients due to atonic $\mathrm{PPH}$, excessive bleeding due to extension of uterine incision. In one case injury to bladder was observed with previous history of LSCS two times. Majority of patients $(41 \%)$ had blood stained urine due to drawn up bladder, edematous and congested bladder wall and very close proximity to lower uterine segment and bladder.

Table 4: Intra operative complications.

\begin{tabular}{|lll|}
\hline Complication & Number & Percentage \\
\hline Atonic PPH & 35 & $35 \%$ \\
\hline Uterine incision & 28 & $28 \%$ \\
\hline Angle hematoma & 9 & $9 \%$ \\
\hline Uterine artery ligation & 13 & $13 \%$ \\
\hline Hematuria & 41 & $41 \%$ \\
\hline Bladder injury & 1 & $1 \%$ \\
\hline Blood transfusion & 8 & $8 \%$ \\
\hline
\end{tabular}

Total no. may exceed 100 as multiple complications were observed.

Table 5: postoperative complications.

\begin{tabular}{|lll|}
\hline Complication & Number & Percentage \\
\hline Febrile illness & 12 & $12 \%$ \\
\hline Wound infection & 9 & $9 \%$ \\
\hline Wound resuturing & 4 & $4 \%$ \\
\hline Prolong catheterization & 42 & $42 \%$ \\
\hline Abdomen distension & 3 & $3 \%$ \\
\hline Prolong hospital stay & 49 & $49 \%$ \\
\hline
\end{tabular}

Table 6: Neonatal complications.

\begin{tabular}{|lll|}
\hline Complication & Number & Percentage \\
\hline Nursery admission & 44 & $44 \%$ \\
\hline Birth asphyxia & 16 & $16 \%$ \\
\hline Meconium aspiration & 8 & $8 \%$ \\
\hline Neonatal jaundice & 8 & $8 \%$ \\
\hline Respiratory distress syndrome & 11 & $11 \%$ \\
\hline Fresh still birth & 1 & $1 \%$ \\
\hline
\end{tabular}

Table 5 shows post-operative complications like febrile illness was observed in $12 \%$ of cases due to prolonged second stage of labor, ruptured of membrane, multiple per vaginal examinations. Wound infection was found in 9 cases. Out of these 4 required re-suturing and rest were managed conservatively. 3 patients had abdomen distension which was managed conservatively. In $42 \%$ patient, catheter was kept for long time. Overall $49 \%$ of the patients had to stay in hospital for $>7$ days.
Table 6 shows the neonatal outcome. In our study, 44 babies were admitted to nursery, most common complication being birth asphyxia (16\%). Rest complications included meconium aspiration, RDS, neonatal jaundice and one fresh still birth.

\section{DISCUSSION}

In our study of 100 patients, most of the patient were in the age group 21-30 year and booked. Majority of patients undergoing 2nd stage cesarean sections were primigravida $(81 \%)$ which may be due to mild to moderate cephalopelvic disproportion, rigid perineum, lack of experience of previous labour in primigravida women. In the study by Malathi and Sunita, $61 \%$ women were in the age group of 21 to 30 years. ${ }^{9}$ Same results were also found in study done by Feinstein et al and Sandya et al. ${ }^{10,11}$

Most common indications of $2^{\text {nd }}$ stage cesarean sections were cephalopelvic disproportion (27\%) followed by fetal distress $(21 \%)$. In the study by Kumaresan $\mathrm{S}$ et al, most common indications were also cephalopelvicdisproportion $(34.8 \%)$ and non-reassuring fetal heart rate patterns $(18.4 \%) .{ }^{12}$ Same results were also observed in study by Gurung $\mathrm{P}$ et al. ${ }^{13}$ As the duration for second stage increases, there would be more difficulties in delivering the baby because of edematous lower segment, overstretched and thinned out lower segment and more impaction of presenting part in pelvis. In our study, $44 \%$ of the babies were delivered by vertex followed by Patwardhan $(31 \%)$. Rest was delivered by push method and breech extraction. This is similar with the study by Babre VM et al, in which deeply engaged head delivered by vertex method in $67.2 \%$, by Patwardhan method in $23 \%$ and by push method in $9.8 \% .^{14}$

In our study $41 \%$ patient had hematuria and uterine atonicity was encountered in $35 \%$ of patients, most of which were treated by medical management, out of which $13 \%$ required uterine artery ligation and $8 \%$ required blood transfusion. Kumaresan $\mathrm{S}$ et al, (atonic uterus $33.2 \%$ and hematuria $34.8 \%$ ) and Sandya et al found the same results.11,12 Uterine incision extension was observed in $28 \%$ and bladder was injured in $1 \%$ cases similar to study by Kumaresan et al. ${ }^{12}$ In postpartum period $12 \%$ of cases had febrile illness similar to study by Jayaram $\mathrm{J}$ et al, $9 \%$ cases had wound infection (Babre VM et al $8.2 \%) .{ }^{14,15}$ Out of these $4 \%$ required re-suturing. Other complications include abdomen distension and prolong catheterization. Nursery admissions (44\%) were significantly high due to birth asphyxia (16\%). We had one fresh still birth. Rest neonates were admitted due to meconium aspiration, RDS and jaundice.

\section{CONCLUSION}

Decision making surrounding second stage cesarean section is often challenging and also there is significantly increase in maternal and neonatal morbidity as well as in 
neonatal mortality following caesarean section in the second stage of labor so involvement of senior obstetrician is desired regarding suitability and safety for trial of operative vaginal delivery or CS as well as skilled obstetrician is required for performing second stage CSection. The main point of focus should be on strict monitoring of normal progression of labor, proper use of the partograph, pain relief measures and judicial use of oxytocin augmentation. Periodic audits regarding the rate of second stage cesarean section are required as well as formulation of an institutional protocol and training and supervision of trainees to improve the skill of operative vaginal delivery and second stage cesarean is needed.

Funding: No funding sources

Conflict of interest: None declared

Ethical approval: The study was approved by the Institutional Ethics Committee

\section{REFERENCES}

1. Asicioglu O. Second stage vs first-stage cesarean delivery: comparison of maternal and perinatal outcomes. J Obstet Gynecol. 2014:1-7.

2. Murray SF, Pradenas FS. Health sector reform and rise of cesarean birth in Chile. The Lancet. 1997;64.

3. Vousden N, Cargill Z, Briley A, Tydeman, G, Shennan AH. Caesarean section at full dilatation: incidence, impact and current management. The Obstet Gynaecol. 2014;16:199-205.

4. McKelvey A, Ashe R, McKenna D, Roberts R. Caesarean section in the second stage of labour: a retrospective review of obstetric setting and morbidity. J Obstet Gynaecol. 2010;30(3):264-7.

5. Panday GV. Second stage caesarean section at a tertiary centre in South Africa, Journal of MaternalFetal Neonat Medic. 2010;23(10)1151-5.

6. Unterscheider J, McMenamin M, Cullinane F. Rising rates of caserean deliveries at full cervical dilatation: A concerning trend. Eur J Obstet Gynaecol Reprod Boil. 2011;157:141-4.
7. Alexander JM, Leveno KJ, Rouse DJ. Comparison of maternal and infant outcomes from primary caesarean delivery during the second compared with the first stage of labor. Obstet Gynecol. 2007;109(4):917-21.

8. Govender V, Panday M, Moodley J. Second stage caesarean section at a tertiary hospital in South Africa. J Matern Fetal Neonatal Med. 2010;23(10):1151-5.

9. Malathi J, Sunita V. Comparison of obstetric outcome between first and second stage cesarean sections in rural tertiary hospital. Int $\mathrm{J}$ Pharm Biomed Res. 2012:222-25.

10. Feinstein U, Sheiner E, Levy A, Hallak M, Mazor M. Risk factor for arrest of descent during the second stage of labour. Int J Gynaecol Obstet. 2002;77(1):714.

11. Sandya MR, George S, Varghese L. Fetomaternal outcome in second stage Caesarean section - An audit. Int J Obstet Gynecol. 2018;6(2):207-10.

12. Kumaresan S, Loganathan M. Rising rates of second stage caesarean section and its impact on maternal outcome. Int J Reprod Contracept Obstet Gynecol. 2018;7:2681-5.

13. Gurung P, Malla S, Lama S, Malla A, Singh A. Caesarean section during second stage of labor in a tertiary centre. J Nepal Health Res Counc. 2017;15(36):178-81.

14. Babre VM, Bendre KR, Niyogi G. Review of caesarean sections at full dilatation. Int $\mathrm{J}$ Reprod Contracept Obstet Gynecol. 2017;6:2491-3.

15. Jayaram J, Mahendra G, Vijayalakshmi S. Fetomaternal outcome in cesarean sections done in second stage of labor. Indian J Obstet Gynaecol Res. 2016;3(1):51-4.

Cite this article as: Gupta K, Garg A. Fetomaternal outcome in caesarean section at full dilatation. Int $\mathbf{J}$ Reprod Contracept Obstet Gynecol 2019;8:3098-101. 